\title{
Using Composite Material in Transportation Pipes of Wheat in Silos
}

\author{
Maryam Yousif Ghadhban \\ The Ministry of higher Education and Scientific Research, directorate of scholarships and cultural \\ relations, Department of Public studying abroad, Iraq - Baghdad - alkarrada - alnidhal Street - near \\ Andalus Square.
}

Rec. 17 Aug, 2010 Accpt. 10 Dec 2010

\begin{abstract}
Resistible composites have been suggest to be used instead of carbon steel pipes to overcome number of common problems during commercial applications, especially the problem of fixing dead-beat carbon steel pipes within these systems. A buildup apparatus studied the wearing in pipes for the carbon steel and composites specimens. The electrical prosperities of the composites resistible material of unsaturated polyester reinforced with glass fiber and aluminum honeycomb were studied to find the best conditions for the constructed pipes. It was found that, by increasing the concentration of aluminum powder up to $50 \%$ of the composite mixture the electrical conductivity increases within the range of semi-conductance (from $1 \times 10^{-4}$ to $10 \times 10^{-4} \mathrm{~S} / \mathrm{cm}$ ). The best concentration of aluminum powder was $30 \%$ of the composite mixture, which represent the most suitable electrical. Also, it was found that aluminum honeycomb samples were a very good electrically conductive $\left(3.7 \times 10^{5} \mathrm{~S} / \mathrm{cm}\right)$ suitable for certain applications.
\end{abstract}

Key words: Composite material, transportation, wheat

\section{Introduction:}

Composite materials were known to mankind in the Paleolithic age (also known as Old Stone age). The $300 \mathrm{ft}$ high ziggurat or temple tower built in the city center of Babylon was made with clay mixed with finely chopped straw (Maleque, 2007). In recent years, polymeric based composite materials are being used in many applications, such as automotive, sporting goods, marine, electrical, industrial, construction, household appliances, etc. Polymeric composites have high strength and stiffness, light weight, and high corrosion resistance (Wallenberger and Weston, 2004). Nowadays market challenges, based on economy and efficiency of the manufacturing process, as well as various customers' needs, resulted in the development of new and high quality materials, such as composites. Scientists have defined composite materials in many ways (Zgura et al., 1999; Iordache et al., 1996). but the common idea of all these definitions is that composites represent artificial materials, made of two basic, notmixable, components represented by the matrix and the reinforcing elements (Mihaiela, 2009). Composite materials (or composites for short) are engineered materials made from two or more constituent materials with significantly different physical or chemical properties which remain separate and distinct on a macroscopic level within the finished structure. The physical properties of composite materials are generally not isotropic (independent of direction of applied force) in nature, but rather are typically orthotropic (different depending on the direction of the applied force or load). For instance, the stiffness of a composite panel will often depend upon the orientation of the applied forces and/or moments. Panel stiffness is also dependent on the design of the panel. For instance, the fiber reinforcement and matrix used the method of panel build, thermoset versus thermoplastic, type of weave, and orientation of fiber axis to the primary force.

\footnotetext{
* Corresponding author:

Dr. Maryam Yousif Ghadhban

凶mariammeme2004@yahoo.com
} 
In contrast, isotropic materials (for example, aluminum or steel), in standard wrought forms, typically have the same stiffness regardless of the directional orientation of the applied forces and/or moments.

Pneumatic conveying systems can be developed into a completely interconnected. Ready to go; pushbutton grain conveying systems. They are especially adaptable to systems that need relatively low grain conveyeing capacity and where the material is to be a conveyed long distance (greater than 100 feet).

There are two types of pneumatic systems - positive pressure (push) units and negative pressure (vacuum) units. Many pneumatic conveyors use both positive and negative pressure. Grain is vacuumed from a bin, and then pushed into a truck or storage. Air pulled by the blower through the air intake near the grain nozzle. The blower pulls the grain and air into the cyclone, where the grain and air are separated; then the air is pulled through a screen into the blower and is blown out to pick up the grain again. The grain drop down in the cyclone and is metered through the air lock into the air coming from the blower. Both the air and grain flow through the pipe to discharge cyclone where the grain is slowed and allowed to drop out the bottom. The air exhausts through the top of the cyclone. a cyclone separated at the termination point may not be used in all applications (Kennath and Helleevang, 1985).

The pneumatic transportation of bulk solids through pipelines has been in existence for over one hundred years. Some of the earlier applications included the vacuum unloading of grain from ships and the extraction of sawdust from timber mills.

When it is necessary to design or evaluate a proposed pneumatic conveying system, it is recommended strongly that the designer obtain as much information as possible on the actual material(s). Armed with the knowledge of steady-state conveying characteristics, it is quite a simple task to determine the minimum conveying velocity, optimal operating conditions for the product, and the pipeline diameter and compressor/ blower rating.
Wear in bulk materials handling plant may result from impact or abrasion or, as is often the case, a combination of both. Erosive wear due to impact occurs when streams of bulk solid particles impinge, usually at medium to high velocity, on inclined surfaces. Typical examples include the intake end of chutes, bin and hopper walls subject to impact loading during filling. In the case of the pneumatic conveyor systems, erosive bend wear can be quite substantial due to the high velocity of particles in the air stream. (Johanson and Royal, 1982).

1. Abrasive or rubbing wear occurs when the bulk solid flows along the walls of bins and chute. Wear in this case is a combination of pressure and rubbing velocity (Roberts, and Oomsm, 1985 ).

2. Despite the considerable amount of research and investigation into the subject of abrasive wear, there is limited information pertaining directly to the wear in bins and chutes. (Johanson and Royal, 1982). have developed a special abrasive wear

3. apparatus to permit quantitative wear tests to be performed a hopper and chute lining materials. They also analyzed the wear in storage bins, the same idea, in conceptual form, was also indicated by Roberts (Roberts, and Ooms, 1985).

Abrasive wear assumed that the wear is a direct relation between the normal pressure, the friction coefficient and the rubbing velocity (Roberts, and Ooms, 1985).

$$
w=\sigma_{w}\left(v_{s}\right.
$$

In the analysis that follows in the next section it is assumed that simple wear occurs for which $\mathrm{n}=1$.

"fast" flow in chutes, where the bulk solid moves as a continuous stream, the abrasive or rubbing wear may be determined as follows:

Consider the general case of a curved chute of rectangular cross-section as shown in (Figure 1); an abrasive wears factor Wc 
for rubbing against the chute bottom is given by (Roberts and Ooms, 1985).

$$
\mathrm{W}_{\mathrm{c}}=\frac{\mathrm{F}_{\mathrm{n}} \mathrm{v}_{\mathrm{z}} \tan \alpha}{\mathrm{B} \Delta \mathrm{s}}
$$

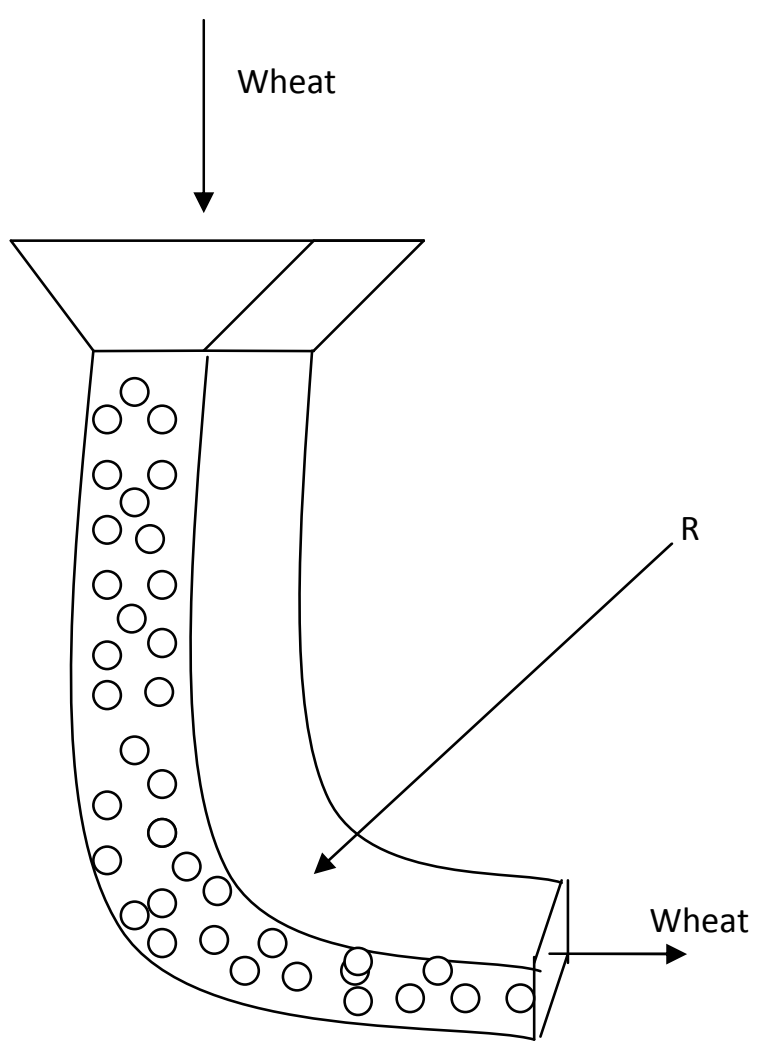

Figure, 1, Curved chute of rectangular crosssection

Davis (Hansen and Tomkiewicz, 1975). found that electrically conductive particles can be added to a polymer (poor conductor) to produce a composite of enhanced electrical conductivity and these composites can also be a good heat and magnetic conductivity.

All these new materials offer certain advantages, but also disadvantages, when compared to elemental metals or their alloys with metalloids. For example, polyacetylene having almost the same electrical conductivity of copper $\left(6^{*} 10^{5} \Omega^{-1} \cdot \mathrm{cm}^{-1}\right)$ (Lai, 2000; Jyh-Ming and Kuo-Weichen ,2000). investigated the electrical conductivity of discontinuous filamentreinforced unidirectional composites. They used copper filament with lengths 0.5 to 11 $\mathrm{cm}$ with volume fraction of 8 and $36 \%$, and the matrix materials included solder and epoxy, they was found that the composite electrical conductivity increases with filament length and eventually becomes a constant. They were found that there was a critical filament length that must be exceeded so the composites will exhibit an electrical conductivity. (Dilhon and Elvan, 2002). studied the affect of the degree of mixedness of graphite, carbon, $\mathrm{Al}, \mathrm{Au}, \mathrm{Ag}$, $\mathrm{Cu}$ and stainless steel powders (electrically conductive filler) when distributed into an insulating polymer. They found that when the time of mixing increase, the electrical conductivity decrease because of the better coating and hence the insulation of the conductive particles from each other. Lai, 2000. have investigated banana fiber reinforced polyester composites and found that the optimum content of banana fiber is $40 \%$. Mechanical properties of bananafiber-cement composites were investigated physically and mechanically by Corbiere(Nicollier et al., 2001; and Mihaiela et al., 2009). they represent experimental and theoretical studies for determining random reinforced glass fiber polymeric composite material mechanical characteristics, pointing out the importance of knowing real values of these characteristics in parts designing. The obtained results are, also, confirmed by statistical data processing while, importance of the involved studies is evidenced by a case study finite element ANSYS simulation

\section{Aim of the Work:}

The present study deals with wear as phenomena in carbon steel pipes used wheat transportation in silos. Also it contains an attempt to fluid a composite material to overcome the wear occurrence. The electrical properties of proposed composite material were tested to insure its suitability as a substituted material for low carbon steel pipes.

\section{Experimental work:}

(Figure 1). shows 3D-schematic diagram of the experimental apparatus. The bin was designed as shown in (figure 2). The bin consisted of two parts (cylindrical and semiconical). 


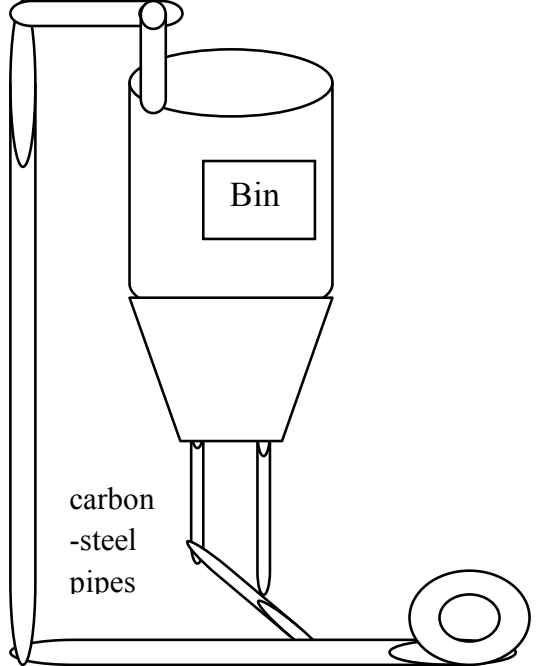

Figure 2, schematic diagram of the experimental apparatus

The bin was designed as shown in (figure 3). The bin consisted of two parts (cylindrical and semi-conical). Both were made of aluminum. The cylindrical part was with an inside diameter of $60 \mathrm{~cm}$ and height of $75 \mathrm{~cm}$. the semi-conical part was with a height of $52 \mathrm{~cm}$ and with two ends, the wide one was of $60 \mathrm{~cm}$ inside diameter and the outer end was with $30 \mathrm{~cm}$ an inside diameter. This bin was used as the main wheat container during the experimental work. Low carbon-steel pipes with an inside diameter of $3.8 \mathrm{~cm}$. These pipes were welded to each other in different angles (35, 45 and $90^{\circ}$ ) as the main pipe angles in the silo. An air blower $(\mathrm{HP}=0.5$, power $=0.5 \mathrm{~kW}$, speed $=2880 \mathrm{rpm}$, type Eopk 80c-2) under the commercial name (Elprom) was used to circulate the wheat delivered from the bin through the pipes in a complete closed loop path Low carbon-steel pipes with an inside diameter of $3.8 \mathrm{~cm}$ were arranged. These pipes were welded to each other in different angles $\left(35,45\right.$ and $\left.90^{\circ}\right)$ as the main pipe angles in the silo

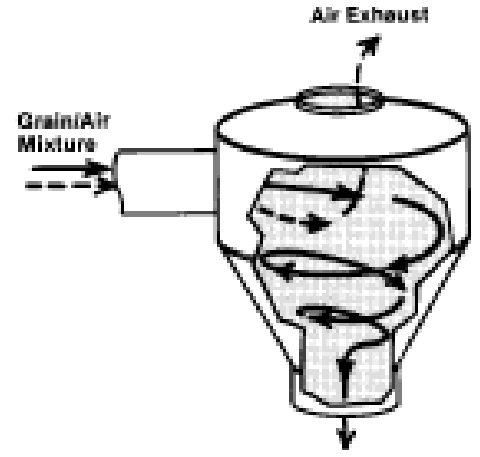

Figure 3, The dimensions of the bin

The raw material foodstuff used in this research was wheat. It's a granular material with a uniform corpuscular shape. Composites raw materials Unsaturated polyester (UPE) , Methyl-ethyl ketone peroxide is a catalyst, Cobalt octoate was used as an accelerator, which is a liquid, A chopped strand mat glass fiber was used with specific gravity of 2.58 , A commercial spheroid aluminum powder of approximately $100 \mu \mathrm{m}$ in diameter was used to make the resin electrically conductive. An aluminum honeycomb was used a as a conductive filler.

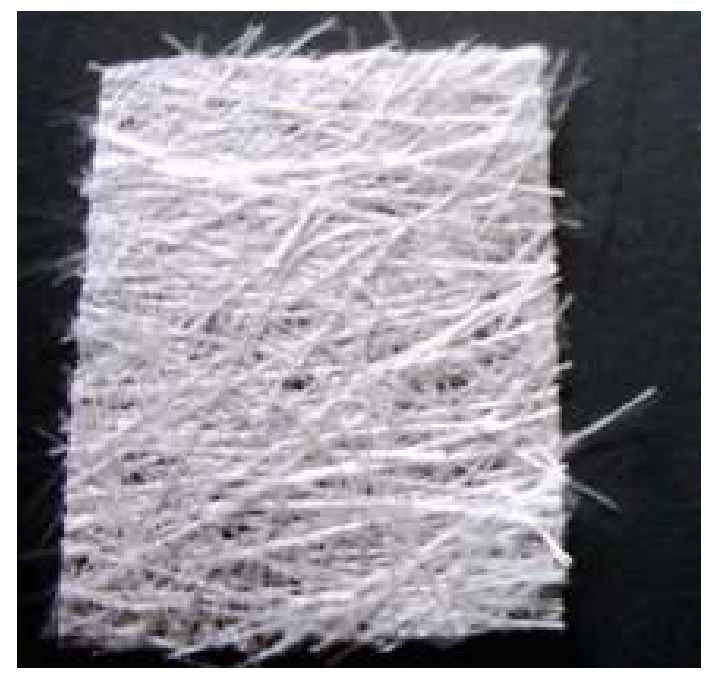

Figure 4, the chopped strand mat glass fiber 


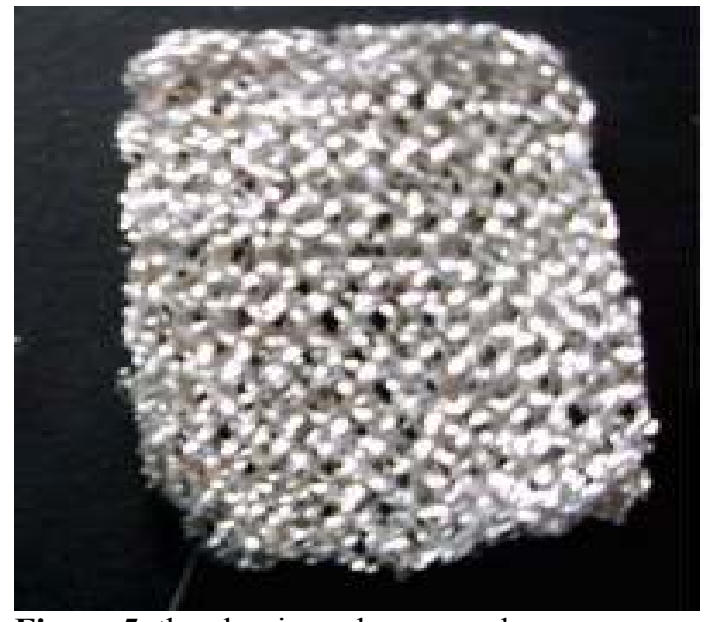

Figure 5, the aluminum honeycomb

The wear behavior of carbon-steel piping in this investigation was carried out using weight loss technique under controlled conditions of wheat flow rate, different angles of flow, constant pipe diameter and pneumatic conveying of wheat. The experiment time was 10 hours. After the carbon-steel specimens were investigated, the composite specimens were investigated in the same conditions, but the time of the experiment was doubled (20 hours). 32 experiments were made, 4 experiments for each sample of composites prepared, in addition to a 4 experiments for the carbonsteel specimens. Ring specimens were prepared with dimensions of $4.8 \mathrm{~cm}$ outside diameter, $1.0 \mathrm{~cm}$ width and $0.5 \mathrm{~cm}$ thickness with exposing surface area of about 11 $\mathrm{cm}^{2}$ to the wear media. After cutting the carbon-steel specimens they were annealed in vacuum at $600^{\circ} \mathrm{C}$ for 1 hour and cooled under vacuum at room temperature, abraded in sequence using emery paper of grade number 220-320, then washed with running tap water flowed by de-ionized water, then dried with clean tissue, degreased with benzene, dried, degreased with acetone, dried and finally left to dry for one hour in a disicator over silica gel. Weighted the specimens were carried out using a 4 decimals electronic digital balance (type BP211D-OCE Sartorius, maximum capacity equal to $300 \mathrm{~g}$ and reliability $0.01 \mathrm{mg}$ ). The dimensions of the specimens were measured with a vernia. Measurement of weight loss is probably the most widely used method to measure wear rate. A typical procedure is as follows: a specimen of known surface area and mass is exposed to the wear test poem for a fixed period of time (10, 20 hours). The loss of metal as a result of wear is then determined from the loss of mass in the specimen after removal of wear product or other deposits from the metal surface. Mass loss values are usually recorded together with the exposed surface area of the specimen and the time length of the test. Frequently the data are expressed as mass loss per unit area per unit time, e.g. mg. dm ${ }^{2}$. $\mathrm{d}^{-1}$ (mdd). The composite samples were prepared for electrical tests using a glass block with cover $\left(8^{*} 6^{*} 2 \mathrm{~cm}\right)$, greased with AP101 grease. The glass fiber was cutted into pieces $7.5 * 5.5 \mathrm{~cm}$ for each $2 \mathrm{~mm}$ thick of the unsaturated polyester resin, a one piece of glass fiber was used. Then the glass fiber pieces were dried in the oven for 1 hour at $120^{\circ} \mathrm{C}$, then the cobalt octoate was added to the resin (for $1000 \mathrm{~g}$ of the resin, a $5 \mathrm{~g}$ cobalt octoate was used), for the hardening of the composite material, mixed well, after that methyl-ethyl ketone peroxide was added to the mixture (for $1000 \mathrm{~g}$ of the resin, $15 \mathrm{~g}$ of methyl-ethyl ketone peroxide was used), as a catalyst for the cross linking ,mixed well, then the aluminum powder was added to the mixture within different weight percent from 10 to $50 \mathrm{wt}$ \%, mixed well for 1 minute, then spill it in the glass block with the glass fiber pieces, covered with the glass cover, it was left at room temperature for 8 hours (curing time). The aluminum honeycomb was used instead of the aluminum powder and the glass fiber (the thickness of the aluminum honeycomb used is the same of the resin). (Figure 6,7). and 8 show the composite's samples prepared.

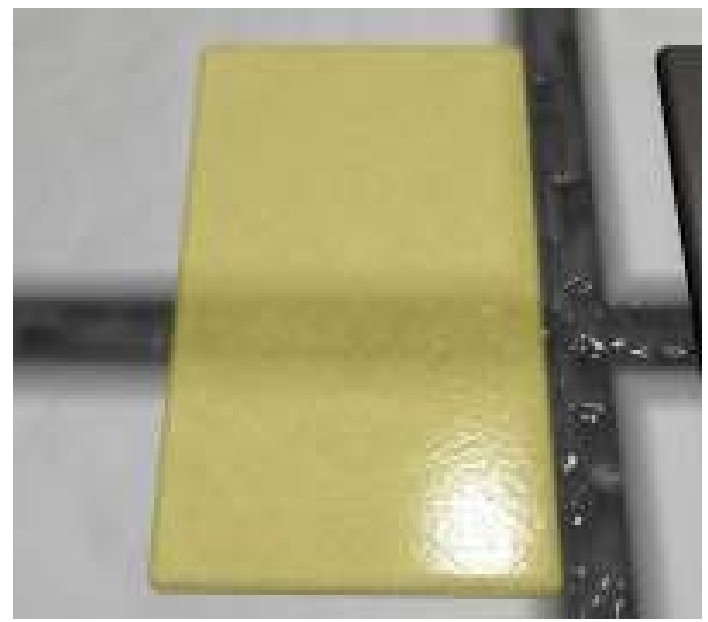

Figure 6, Unsaturated polyester with fiber glass 


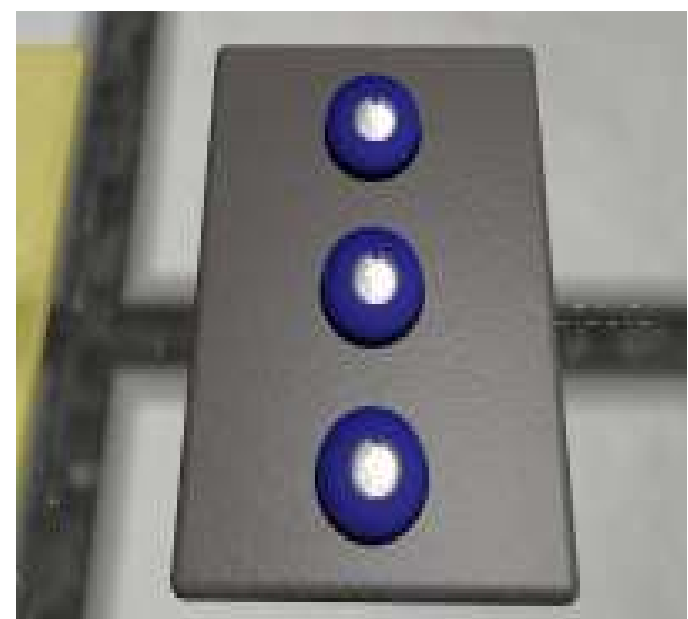

Figure 7, unsaturated polyester with fiber glass $\&$ aluminum powder

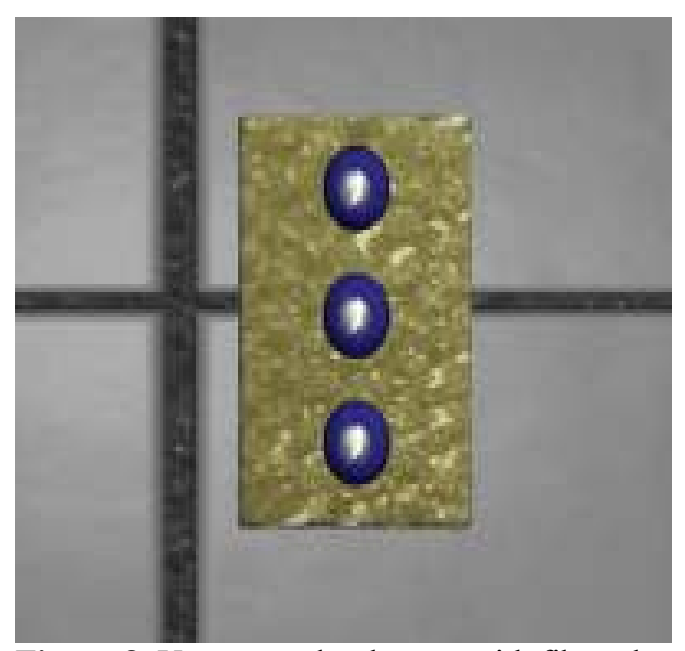

Figure 8, Unsaturated polyester with fiber glass $\&$ aluminum honeycomb

This test method covers a direct-current procedure for the determination of $\mathrm{d}-\mathrm{c}$ volume and surface resistivity of electrical insulating materials, or their corresponding conductivities. The composite specimens were prepared as shown in (figure 9). This test was carried out using an insulation resistance tester device (Yokogawa 3213-21 type). Battery operated as shown in (figure $10)$.

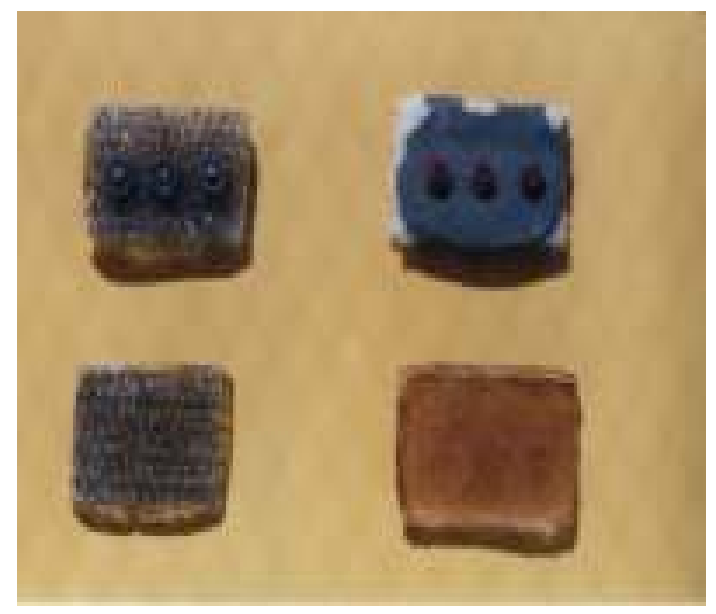

Figure 9, The specimens preparation

The two electrodes of the device were connected with the screws on the specimen, an electrical charge was given using the bottom on the device (100 volts), and the reading of the resistance $(\Omega \mathrm{M})$ was taken from the device scale.

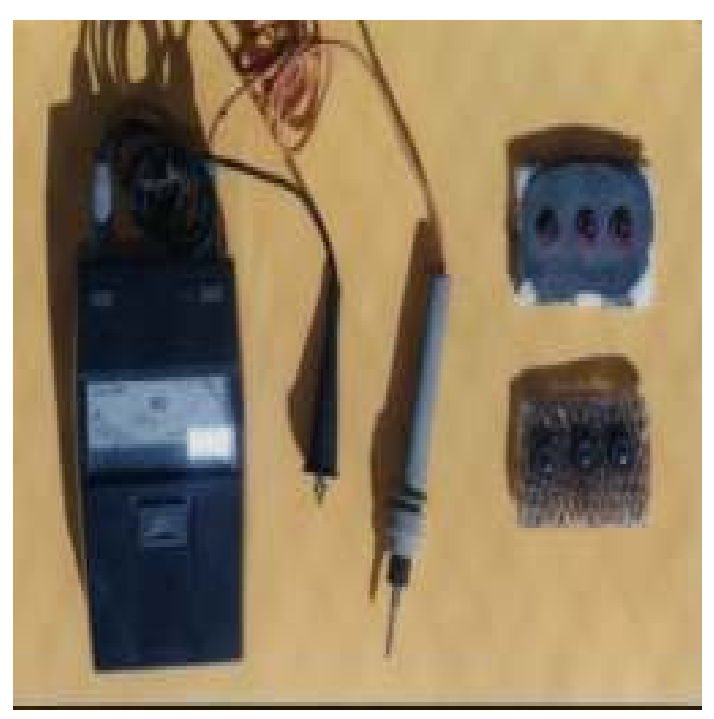

Figure 10, the Electrical Conductivity Device 


\section{Result and Discussion:}

The effect of inclination angle on the flow rate of solid particles was studied by many authors like Trees (1962) since the early beginning of silos design. Figure 11 represent the effect of inclination angle on the flow rate of wheat at different gate open. It can be notice that, for each curve (each gate open) the wheat flow rate increases with increasing inclination angle (the angle to the horizontal). This behavior can be explained due to the free fall of particle, when the particle fall down freely it will have the maximum velocity due to its weight but when the particle hits the bottom of the pipe its velocity will decrease due to the analyzation of weight into two components and also due to friction force.

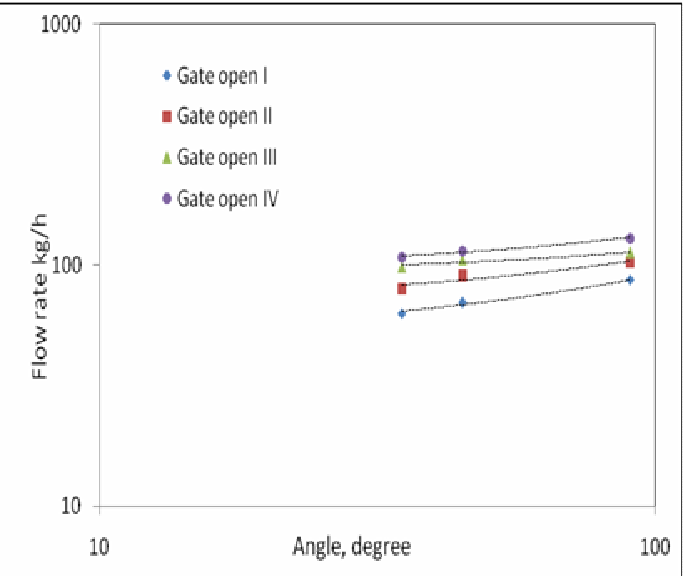

Figure 11, Effect of inclination angle on the flow rate of wheat

It is important to notice that, the angles investigated in the present work shows the same effect on all the gate open flow rates. That all the curves sheared the same slope in all cases (slope $=0.2$ ). This will give us an equation to explain this system. (Trees, 1962 ).

$$
F=k d^{n} \theta^{m}
$$

Because the diameter of pipes is constant in this work, $\mathrm{n}=0$.

$$
\begin{aligned}
& F=k d^{0} \theta^{m} \\
& F=k \theta^{m}
\end{aligned}
$$

Take log:

$$
\log F=\log k+m \log \theta
$$

From the figure $m=0.2$. (for all curves),

$$
\bar{F}=k \theta^{0.2}
$$

Wear in transportation pipes, is one of the major problems in seeds silos. This wear can be noticed by the weight loss technique that occurs within the pipes (specimens). Several tests were made within all angles investigated to show the degree of wear made by the flowing wheat by measuring the weight loss. Figure 12 represents the effect of wheat flow rate on the pipes' wear and each curve represents one of the angles investigated $\left(35,45\right.$ and $\left.90^{\circ}\right)$. It can be noticed that the weight loss increases with increasing the wheat flow rate (increasing the gate opening) for each angle, which gives the idea that by increasing the wheat flow rate, the degree of chaotic movement of the solid globels increases and on the wall which will increase the degree of friction within this wall. All the mentioned above agrees with equations 1 and 2 . That means by decreasing the angle of inclination the weight loss decreases and that was due to the decreasing in wheat flow rate within these angles which means decreasing the degree of turbulence (Roberts, and Ooms).

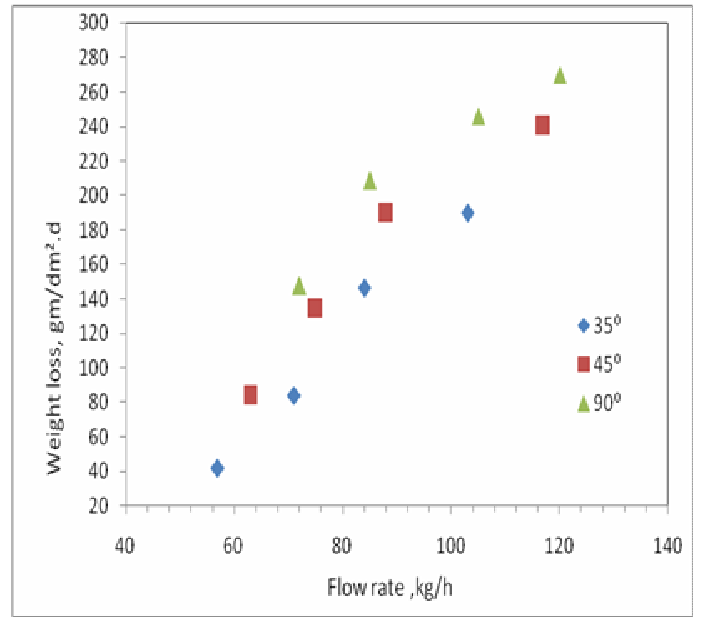

Figure 12 Wheat flow rate against weight loss of carbon-steel specimens

Figure 13 represents the effect of increasing the wheat flow rate on the weight loss in the carbon-steel specimens. Each 
curve was for the same gate opening with different angles. It shows the same effect of figure 12 .

When the conductive composite specimens were exposed to the wear media, no effect had been shown on the weight of the specimens even when the time of the experiment had been doubled (20 hours). That would means the composite materials made of unsaturated polyester with fiberglass have shows a very good resistance to the wearing caused by wheat flow rate (in the range of this research).

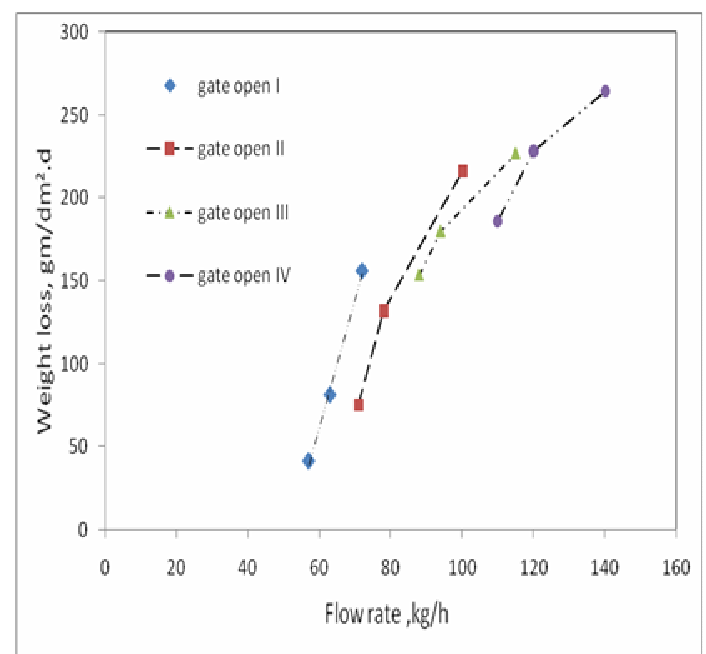

Fig. 13, Wheat flow rate against weight loss of carbon-steel specimens

\section{Electrical conducting test}

This test was made to ensure the electrical conductivity of the composites samples and as we can see in figure 14 the 0,10 and 20 $\mathrm{wt} \%$ of the aluminum powder samples were in the insulation region of table 2.5 of the electrical conductivity. The 30,40 and 50 $\mathrm{wt} \%$ of the aluminum powder samples were in the semi-conduction region of table 2.5, while the carbon-steel and the aluminum honeycomb samples were in the metals

region of the same table. This conducting powder (Al) decreases the electrical resistivity as shown in figure 15 , but the aluminum honeycomb made the composite sample fully conducting (like metals). Figure 16 represent the surface resistivity of the prepared samples it is also, decreases with increasing the aluminum powder concentrations.

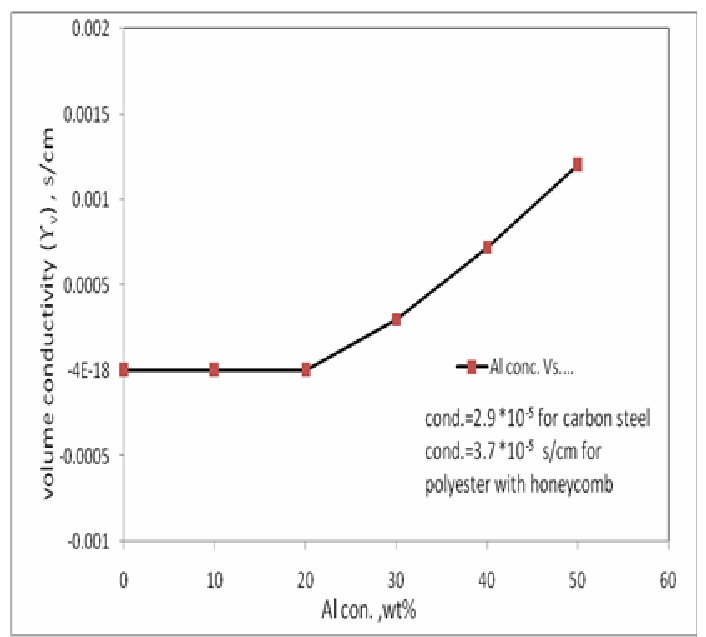

Figure 14 Effect of Aluminum powder concentration on the electrical volume conductivity

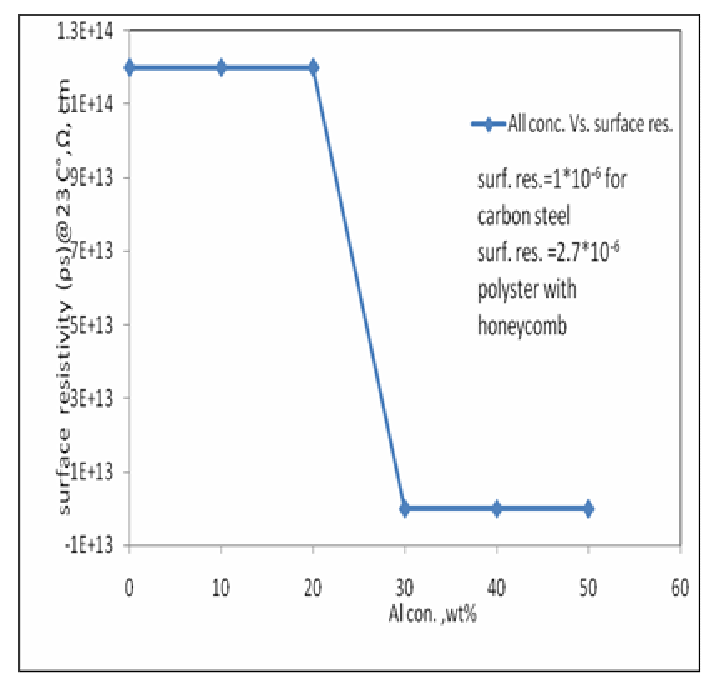

Figure 15, Effect of Aluminum powder concentration on the electrical volume resistivity

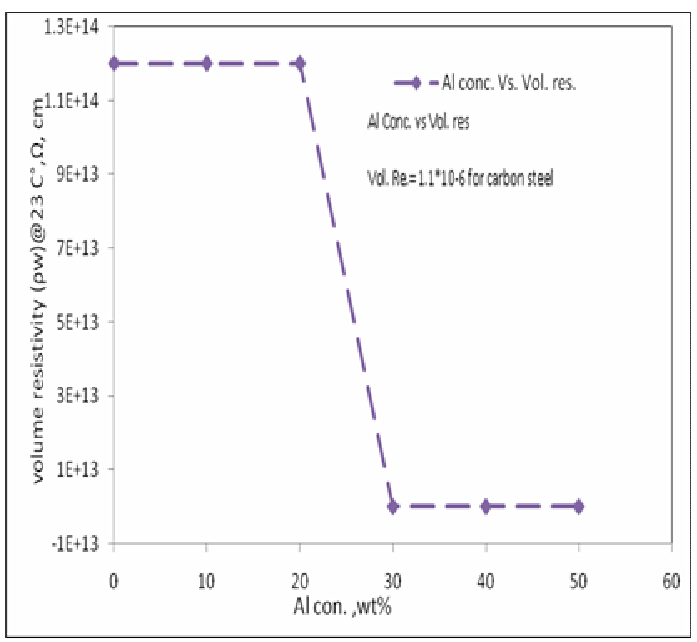

Figure 16, Effect of Aluminum powder concentration on the electrical surface resistivity 


\section{Conclusion:}

The wear of the carbon steel pipes will increase with the inclination angle and the flow rate of wheat. The unsaturated polyester resin reinforced with glass fiber had been shown a good resistible to wearing. The conversion of electrically insulating unsaturated polyester to a conducting material by any amount of aluminum powder will make it a semi-conductor composite suitable to use it as an antistatic material. The electric conducting depending on contact between the conducting particles. So the most suitable weight percent of the aluminum powder is the $30 \mathrm{wt} \%$ because it gives us an electrical conductivity in the semi-conductor range, The aluminum honeycomb sample gives as electrical conductivity in the metal range with specific mechanical properties suitable for specific applications.

\section{Notation:}

$\mathrm{v}_{\mathrm{s}}=$ velocity of sliding against chute bottom $(\mathrm{m} / \mathrm{s})$

$\alpha=$ chute friction angle

$\mathrm{b}=$ chute width (m)

$\Delta \mathrm{s}=$ length of element (m)

$\sigma_{\mathrm{w}}=$ normal wall pressure

$\mathrm{v}_{\mathrm{s}}=$ velocity of bulk solid adjacent to wall

$\alpha=$ wall or boundary friction angle

$\mathrm{n}=$ exponent to allow for any rotation of the particles

$\mathrm{F}_{\mathrm{N}}=\operatorname{Normal}$ force $(\mathrm{N})$

\section{References:}

Wallenberger, F.T. and Weston, N. (2004): Natural Fibers, Plastics and Composites Naturall, Materials Source Book from C.H.I.P.S. Texas,.

Hansen, D. and Tomkiewicz, R.M. (1975). Polymer Engineering and science, vol. 15 , no. 5, pp353-356.

Iordache Gh, S.A. (1996). Componente de $\mathrm{ma}^{\mathrm{o}}$ ini din material polimerice, Calcul. Constructie. Tehnologie; Editura Tehnica, Bucuresti.

Johanson, J.R. and Royal, T. A. (1982). Bulk solids handling, vol. 2, no.3.

Kalyon, D.M. and Birinci, E. (2002). Electrical Properties of Composites as Affected by the Degree of Mixedness of the Conductive Filler in the Polymer Matrix Polymer Eng. \& science, vol. 42 , no. 7, July

kennath, k. and Helleevang, v. (1985). pneumatic grain conveyors",extension agricultural engineer.

Lai, J.H., "Polymers for electronic applications"; $2^{\text {nd }}$ ed. (2000).

Maleque, M.A., Belal F.Y. and Sapuan, S.M. (2007). Mechanical Properties Study Of Pseudo-Stem Banana Fiber Reinforced Epoxy Compositell. The Arabian Journal for Science and Engineering, Volume 32, Number 2B, pp. 359-364.

Mihaiela I., Paulina S., Emil N., Liviu, M. (2009). Experimental and Theoretical Studies on Mechanical Characteristics of an Important Composite Materiall. Materiale Plastice, Vol. 46, No. 1, pp. 62-66.

Roberts, A.W. and Ooms, M. (1995). the university of New Castle, Astralia, "Some aspects of surface friction, adhesion and wear in the gravity flow, handling and belt conveying of nulk solids".

"Rubbn' RepairComposite Repair System". CRG Industries, LLC. Retrieved (2009). 10-02. http://www.rubbnrepair.com/

Joseph, S., Sreekala M. S., Koshy Z. O., Sabu, T. (2002). A Comparison of the Mechanical Properties of Phenol Formaldehyde Composites Reinforced with Banana Fibers and Glass Fibersl, Composites Science and Technology, 62(14), pp. 1857-1868.

Corbière-Nicollier, T., Laban, B.G., Lundquis, L., Leterrier, Y., Månson, J.A.E., Jolliet, O. (2001). Life Cycle Assessment of Biofibers Replacing Glass Fibers as Reinforcement in Plasticsll, Resources, Conservation and Recycling, 33(4), pp. 267-287.

Ting, J.M. and Weinchen, K., Apr. (2000). J. mater. Res., vol. 15 , no. 4 ,

Trees, J. (1962). Trans. Instn. Chem. Engrs., vol. 40.

Zgura, G., Severin, I. (1999). Caracterizarea materialelor composite cu matrice metalica prin tehnici avansate de investigare, Editura BREN, Bucuresti. 


\section{إستخدام المواد المركبة فى أنابيب نقل الحنطة إلى المخازن

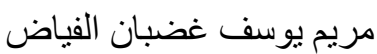

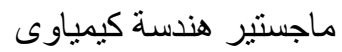 \\ دائرة البعثات و العلاقات الخارجية/ قسم شؤون الدارسين في الخارج}

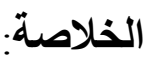

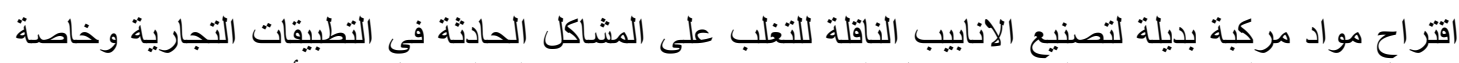

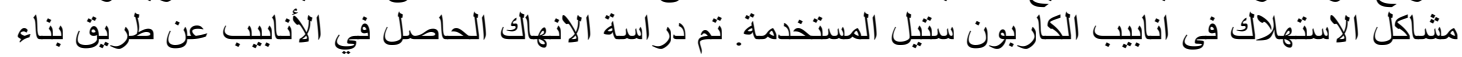

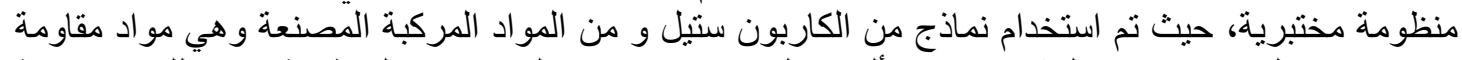

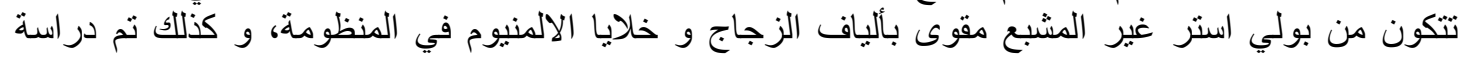

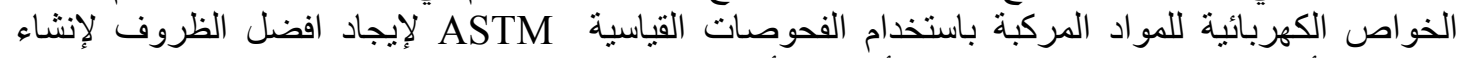

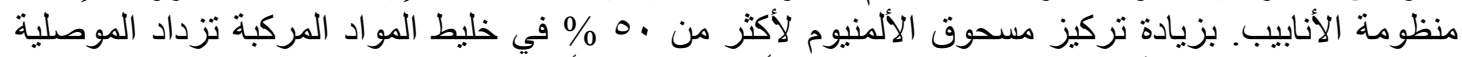

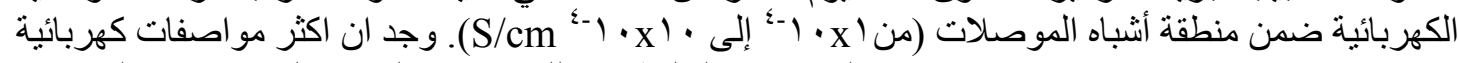

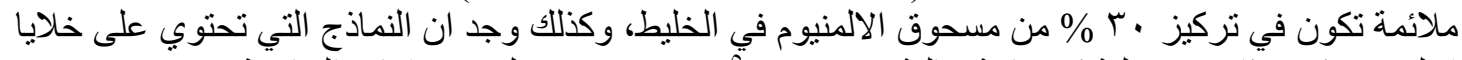

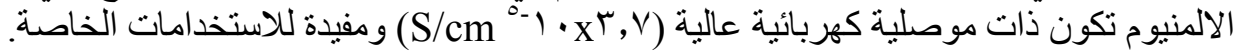

